
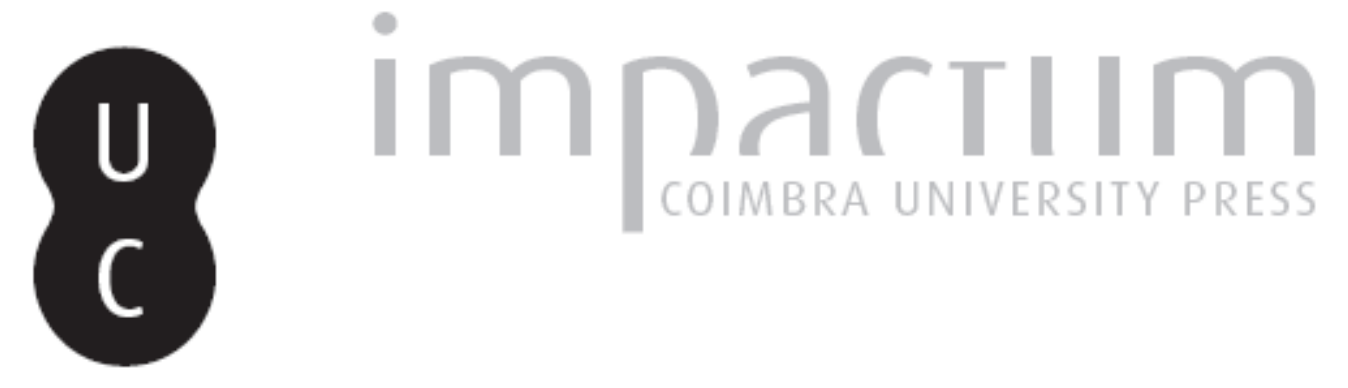

\title{
A história como recordação destruidora
}

\section{Autor(es): Teyssot, George}

Publicado por: Editorial do Departamento de Arquitectura

URL persistente:

URI:http://hdl.handle.net/10316.2/37480

DOI:

DOI:http://dx.doi.org/10.14195/0874-6168_5_1

Accessed : $\quad$ 26-Apr-2023 12:02:22

A navegação consulta e descarregamento dos títulos inseridos nas Bibliotecas Digitais UC Digitalis, UC Pombalina e UC Impactum, pressupõem a aceitação plena e sem reservas dos Termos e Condições de Uso destas Bibliotecas Digitais, disponíveis em https://digitalis.uc.pt/pt-pt/termos.

Conforme exposto nos referidos Termos e Condições de Uso, o descarregamento de títulos de acesso restrito requer uma licença válida de autorização devendo o utilizador aceder ao(s) documento(s) a partir de um endereço de IP da instituição detentora da supramencionada licença.

Ao utilizador é apenas permitido o descarregamento para uso pessoal, pelo que o emprego do(s) título(s) descarregado(s) para outro fim, designadamente comercial, carece de autorização do respetivo autor ou editor da obra.

Na medida em que todas as obras da UC Digitalis se encontram protegidas pelo Código do Direito de Autor e Direitos Conexos e demais legislação aplicável, toda a cópia, parcial ou total, deste documento, nos casos em que é legalmente admitida, deverá conter ou fazer-se acompanhar por este aviso.

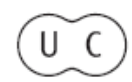




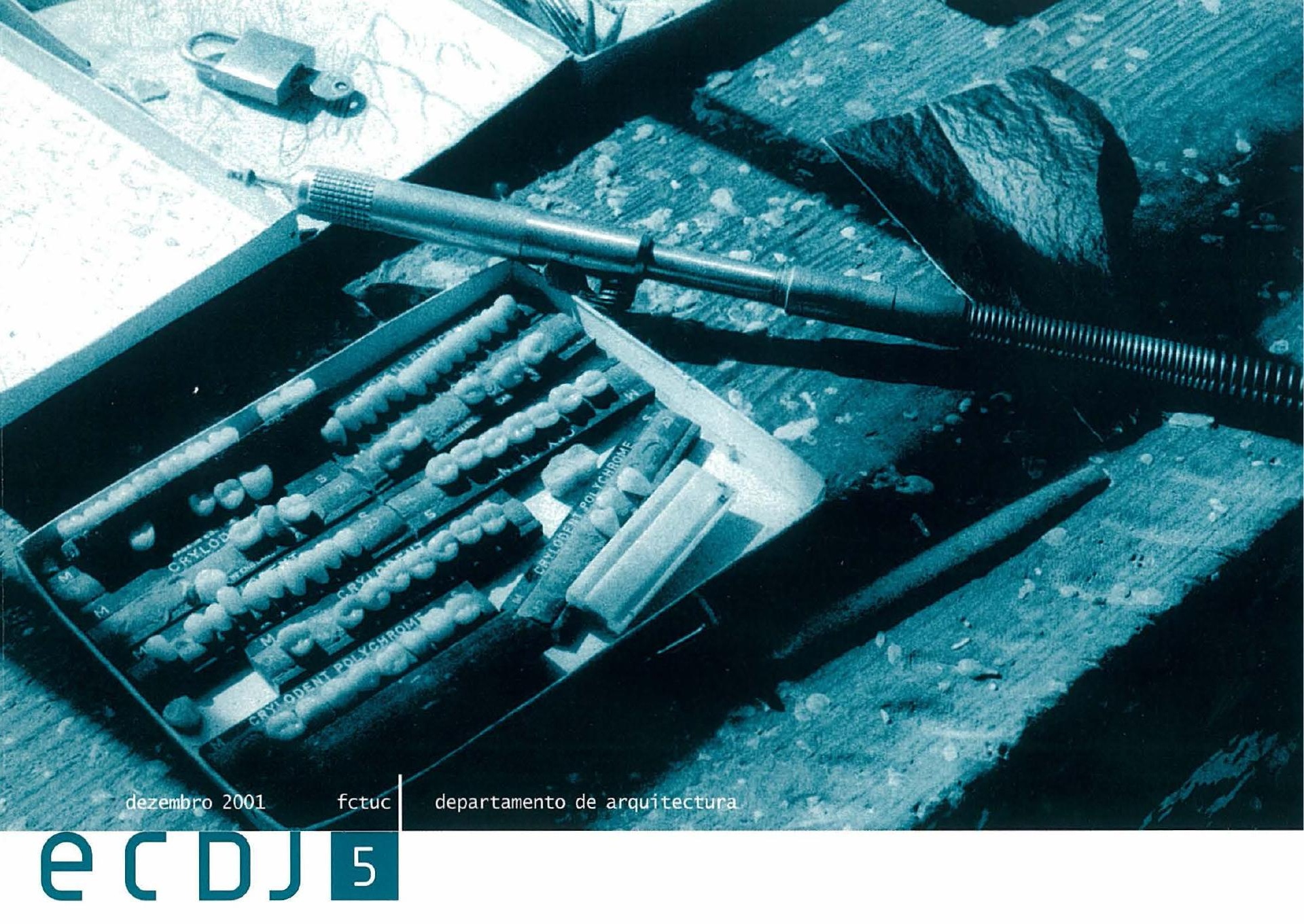

\section{investigação em arquitectura [?]}

George Teyssot

Paulo Providência | Mário Krüger | Wałter Rossa | António olaio

Outra abertura adelino gonçałves

Sti11Life, duração e abandono na obra de john hejduk francisco ferreira

Onde há fogo, nós levamos gasolina pedro bandeira

Apontamentos sobre a arquitectura religiosa do séc. XX em Portugal cidália silva

o desafio ecológico luís pinto faria

Pescada de rabo na boca patrícia miguel carvalho

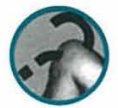



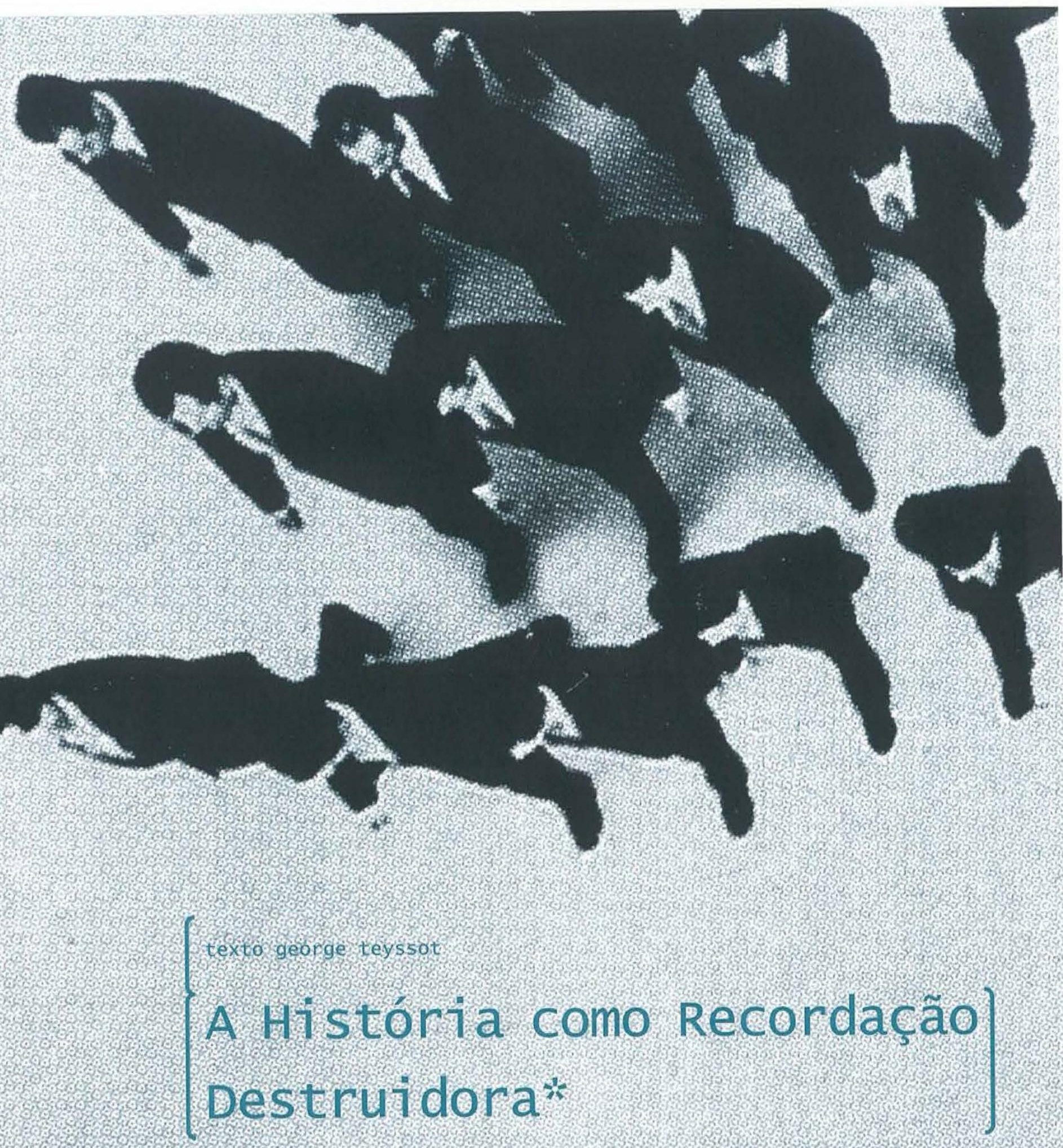


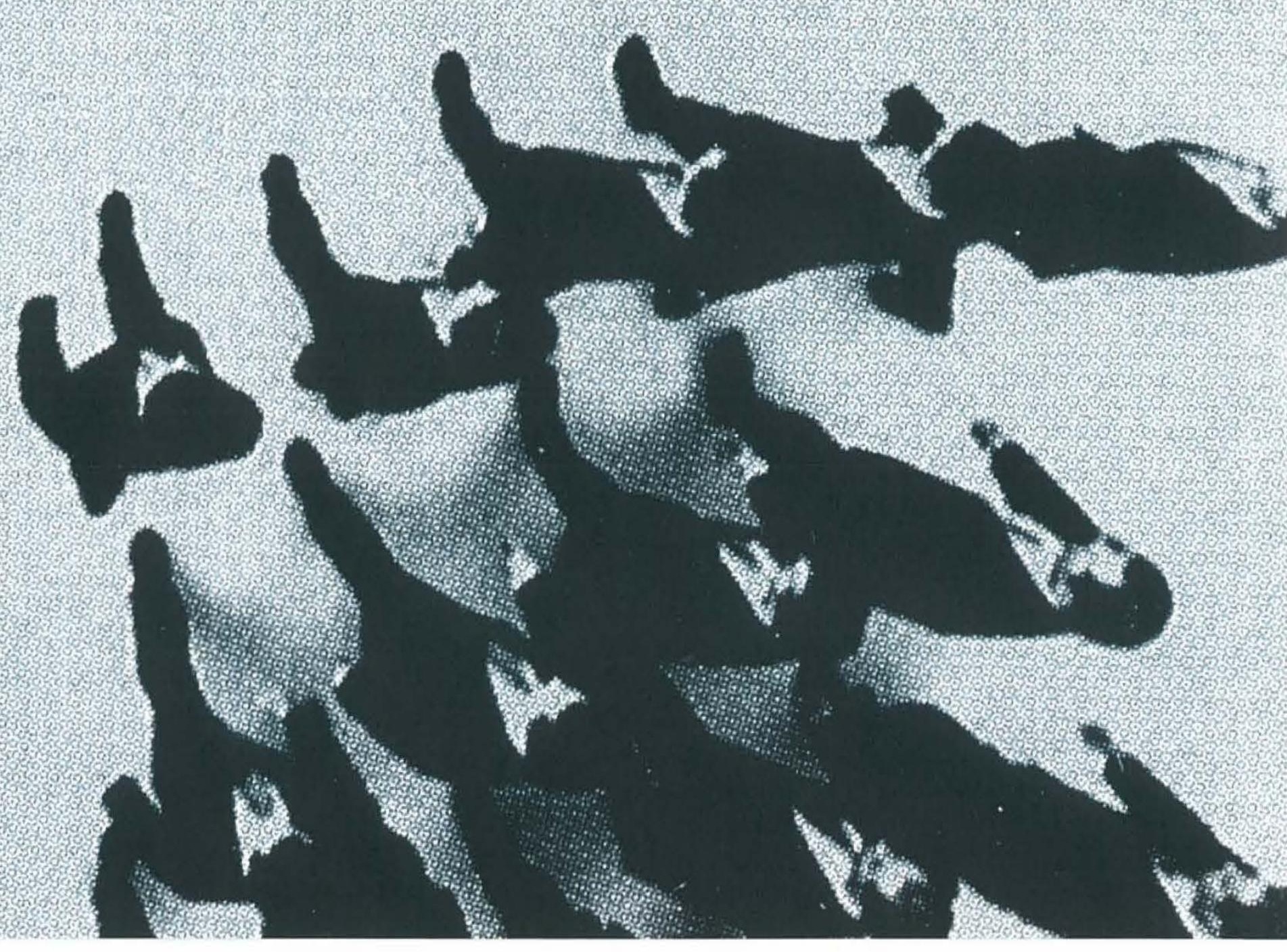


> É possível pensar a tarefa do historiador como a de recolher fragmentos a acrescentar aos já agrupados nas vozes "cidade onírica" (die Traumstadt) e "arquitectura onírica" (das Traumhaus) no Passagen-werk de walter Benjamin. Esta obra, que resultaria num 1ivro sobre as passages ou galerias de Paris, permaneceu em fase de "projecto". A este, Benjamin sobrepunha um plano mais abrangente e ambicioso intitulado paris, Capital do século XIX, do qual existe como forma completa uma relação relativamente breve redigida em 1935 . Como ta1, a obra sobre Paris nunca foi escrita nem poderia sê-10 em nenhum momento. E isto não tanto por causa dos acontecimentos trágicos daquele período, mas porque Benjamin tentava superar a própria "forma" do Tivro de história, balançando entre narrativa e discurso científico: "o Tivro é um intermédio fora de moda entre dois sistemas diferentes de registo", o do investigador e o do leitor.

> Seguindo o caminho indicado pelos irmãos Goncourt e por Rémy de Gourmont (criar a história "com o refugo der - Abfal1 - da história"), e assumindo "o princípio de montagem na história"(1) como modo de procedimento e pensamento, Benjamin quer "erigir as grandes construçōes [historiográficas] a partir de minúsculos elementos recortados com precisão e nitidez. Descobrir de facto, na análise do pequeno momento particular, o cristal do acontecer"(2). Noutro Tugar, reforça: "Método deste trabaTho: montagem Titerária. Não tenho nada a dizer. Só a mostrar. Nã̃o subtrairei nada de precioso e não me apropriarei de nenhuma expressão rica de espírito. Trapos e refugo (die Lumpen, den Abfa11), pelo contrário, mas não para os inventariar, antes para Thes fazer justiça na única forma possível: usando-os"(3). Benjamin, inspirado também pela noção de mémoire involuntaire tomada de proust, compara a actividade do crítico e do historiador 
(as duas são incindiveis) com o que acontece na mente no momento de acordar, após dormir: "O novo método dialéctico da ciência histórica apresenta-se como a arte de ver o presente como o mundo acordado ao qual o sonho, que chamamos passado, na verdade se refere. Refazer o passado na recordação (die Erinnerung) do sonho! Desta forma, recordaçăo e acordar estão intimamente ligados. Quer dizer, o acordar é a revolução copernicana e dialéctica da rememoração (das Eingedenken, trazer à mente)"(4).

> A investigaçăo sobre o século dezanove, focalizada em Paris, assume o significado de uma "proto-história"(5) da modernidade, a qual pode ser capaz de revelar "o vulto sedutor e ameaçador"(6) da técnica no seu início. o século de má reputação, marcado pela condenação estética feita pelas vanguardas artísticas modernas, é visto por Benjamin, jogando com as palavras, quer como época no sentido de espaço-tempo (zeitraum), quer como época onírica (ein zeit-Traum) no qual "a consciência colectiva se abate num sono cada vez mais profundo"(7). A "crítica" do século dezanove torna-se uma espécie de proto-história, de pré-história, ou de arqueologia (die urgeschichte) (8), e consiste numa decifração das palavras do sonho colectivo, do "colectivo sonhante" (das träumende kollectivum). Para isso é urgente, no que respeita ao século dezanove, "não a crítica do seu mecanismo e mecanicismo, mas a do seu historicismo narcotizante, da sua mania pelas máscaras, nos quais no entanto se esconde um sinal de verdadeira existência histórica que os surrealistas foram os primeiros a detectar"(9). Nisto estará talvez o sentido da nota imediatamente seguinte, onde Benjamin escreve: "Tentativa de radicalizar [de ultrapassar] as teses de Giedion. Este afirma: 'no século dezanove a construção reveste o pape 1 do subconsciente'"(10). Tạ "u1trapassagem" é procurada nas correspondências 
que se estabelecem "entre o mundo da técnica e o arcaico universo simbólico da mitologia"(11). Aí Benjamin, apesar das suas próprias afirmações(12), segue não tanto o surrealismo em geral, mas antes precisamente o Aragon de Le Paysan de Paris (Paris 1926), em particular o Préface à une Mythologie Moderne publicado separadamente em 1923. Para Aragon, a "mitologia" do moderno aceita o sentido muito preciso da experiência negativa: "Cada dia se modifica o sentimento moderno da existência. Uma mitologia enreda-se e desenreda-se. É uma ciência da vida, que pertence apenas a aqueles que não a experimentam". Assim, a mitologia moderna é conhecimento, ciência da vida, a qual no entanto iłumina apenas aqueles que já estão fora, ou se sentem removidos, desposados de tal experiência que resulta diferida no tempo e no espaço. Desta forma, o mito é definido como a experiência de um olhar sobre uma outra experiência - por exemplo, a das passages parisienses -, no momento do seu adiamento ou do seu desvanecimento, através de procedimentos de morte, de destruição, ou de desuso. E, visto que o que define esta mitologia é a sua instantaneidade, o seu carácter efémero, “ não é permitido a ninguém de se demorar mais de um instante" no meio dos sonhos (acordados) e das fantasmagorias.

> No Passagen-Werk, Benjamin propöe o derrube da perspectiva desenhada por Sigfried Giedion no seu Bauen in Frankfreich: Eisen, Esisenbeton (Leipzig 1928): "Precisamente como Giedion nos ensina a ver os traços fundamentais da arquitectura de hoje nos edifícios de 1850, nós queremos ver a vida de hoje e as formas de vida presentes, nas formas aparentemente secundárias e perdidas daquele tempo"(13). Talvez esteja aqui, neste último apontamento, a explicaçăo deste aforismo de Benjamin: "compreender Breton e Le Corbusier conjuntamente"(14). Poderíamos traduzir este leitmotiv como uma advertência para compreender Aragon e Giedion conjuntamente.

> 0 propósito historiográfico de Giedion consistia na revelação dos tipos edificatórios e construtivos (Bautyp) do passado camuflados sob a trama da decoração: "o século dezanove revestiu de máscaras historicistas cada nova criação, em todos os sectores: no sector da arquitectura como no da indústria ou no da sociedade [...] Esta máscara historicista está indissoluvelmente ligada à imagem do século dezanove e não deverá ser obliterada". A "radicalização" de Giedion procurada por Benjamin consiste numa reviravolta (Umschlag) através da qual, não tanto o passado (die vergangenheit), mas antes "o-que-foi-uma-vez" (das Gewesene), já não parado e imóve1, irrompe no contemporâneo: "O passado deve tornar-se a inversão dialéctica, a erupção inesperada (Einfa11, ideia súbita, descoberta, mas também derrocada) da consciência acordada"(15). A erupção dos factos históricos, exumados do esquecimento, pode ser obra da recordação 
(die Erinnerung) mas o mecanismo deve assemelhar-se ao acordar: "Aquilo que Proust alude com a experiência da deslocação dos móveis no despertar matutino, aquilo que Bloch define como a obscuridade do momento vivido, não é nada de diferente do que deverá ser assegurado sobre o plano da historicidade, e colectivamente" (16). É preciso ter em conta que Benjamin tem em mente a oposição, desenvolvida por Theodor Reik, entre memória (Gedächtnis) e recordaçăo (Erinnerung): a memória - escreve este - "tem a função de proteger as impressões recebidas; a recordaçăo, pelo contrário, prende-se com a sua desagregação; a memória é essencialmente conservadora, a recordação é destruidora" (17). Igualmente, o facto de acordar do sonho é, enquanto passagem, ruptura e continuidade ao mesmo tempo. Esta dialéctica da passagem, o lugar da mente no limiar entre o acordar e o acordado, faz entrar a figura do acordar no centro das reflexões gnoseológicas de Benjamin. "Há um 'saber-ainda-não-consciente' 'do-que-foi' , cuja trazer à superfície tem a estrutura do acordar"(18). o adormecer e o acordar são ritos de passagem da vida humana; os únicos que restam numa sociedade secularizada. No entanto adverte Benjamin -, "o limiar (schwe11e) deve ser claramente distinguido do limite (Grenze). o limiar (schwelle) é uma zona. Na palavra schwellen [inchar, dilatar-se] estão compreendidas as ideias de mutação, de passagem de um estado a outro, de fluxos e refluxos, significados que a etimologia não deve deixar escapar. Por outro lado é necessário determo-nos no contexto tectónico e cerimonial que levou a palavra ao seu significado"(19).

\section{"Aquilo que Proust alude com a experiência da des7ocação dos móveis no despertar matutino, aquilo que Bloch define como a obscuridade do momento vivido."}

0 acordar não é suspensão, mas estabelece uma porta a atravessar com toda uma série de ritos, entre o mundo do sonho e o estado de acordado. É uma zona conformada de uma precisa tectónica, uma região de cognição. Passagem e peristilo, pronao e portão, entrada e vestíbulo, arco de triunfo, pro-fano e sacro: estas Tinhas, imaginárias e tectónicas, năo criam limites, mas uma área entre, um espaço no meio. A forma do limiar, como figura temporal e espacia1, é a do "entre-dois" (do 1 'entre-deux), do medium que abre entre duas coisas ou duas pessoas. O passagen-Werk é, entre tantas outras coisas, um esboço de uma "ciência dos 1 imiares": "o terror que a campainha faz reinar despoticamente no apartamento, também tira a sua força do feitiço do Timiar. um som agudo anuncia que qualquer coisa está a atravessar o limiar"(20). 
> Numa passagem dos primeiros apontamentos para o seu trabalho(21), onde se reclama a noçăo de percepção como função do tempo desenvolvida por Bergson em Matiére et Mémoire, Benjamin obriga-se, para entender até ao fundo a natureza das passages, a precipitar-se "no sonho mais profundo", de tal forma que as coisas, submergidas num fluxo contínuo, The venham ao encontro. o passo seguinte parece ser concluído através da leitura de um artigo do doutor Pierre Mabille, publicado na revista "Minotaure" em 1935, no qual se contrapõe o "inconsciente vital" (individual) e o "inconsciente do esquecimento"; o segundo, de natureza prevalentemente colectiva, é um inconsciente que chega "da massa das coisas aprendidas durante as épocas e durante a vida, que foram conscientes e que por difusão, entraram no esquecimento". os elementos do inconsciente individual desvanecem, desaparecem; subsistem apenas os do inconsciente colectivo, "induzidos do mundo exterior [e] mais ou menos transformados e digeridos". Emerge a possibilidade de um interior do "colectivo", interioridade feita de coisas exteriores, conservadas como num vaso informe.

"...da massa das coisas aprendidas durante as épocas e durante a vida, que foram conscientes e que por difusão, entraram no esquecimento."

> Uma noção idêntica aparece nos apontamentos de Benjamin, para quem "grande parte do que para o indivíduo é exterior pertence na colectividade à própria interioridade: arquitectura, moda, até o tempo atmosférico, săo, no interior do colectivo, aquilo que os processo orgânicos, os sintomas de doença ou de saúde, são para o interior do indivíduo"(22). Ao contrário do terapeuta-analista que quer desmascarar as figuras do sonho, a "hermeneutica" benjaminiana pelo contrário propöe-se fazer emergir nos edifícios, nas coisas aparentemente mais utilitárias tudo o que as liga ao sonho, quer dizer ao irraciona1, ao sepulto, à doença, ao digerido, ao perturbante. É aqui que está a força da analogia que permeia o Passagen-werk, e que constitui de forma explicita dois dos seus capítulos de apontamentos e reflexões, recolhidos sob o tema da "cidade onírica" (die Traumstadt) e da "arquitectura onírica" (das Traumhaus). A analogia sonho-arquitectura estabelece as "correspondências" (a noção chave da teoria poética de Baudelaire) entre o mundo do sonho e o das coisas. Torna-se agora claro o significado de uma anotaçăo deste tipo:" A moda e a arquitectura pertencem à obscuridade do instante vivido, à consciência onírica do colectivo, que se desperta, por exemplo, na publicidade"(23). 
> Autor de uma montagem surrealista, idêntica à colagem da arte modernista, Benjamin também constrói algo com as suas citações: coleccionador e flâneur de biblioteca, ele recolhe os fragmentos para construir uma história. Tais fragmentos não conduzem à estetização do fragmentário, receita do projecto moderno, mas revelam as formas historicistas de cada fragmento recolhido. o observatório aparentemente caótico do século XIX, constitui-se assim não como período histórico remoto e imóve1, a estudar através de monografias de artistas e arquitectos, ou estudos de tipos edificatórios (Bautyp), mas como regiões espaço-temporais, como uma vasta zona intermédia "onde a estética e o social năo adquiriram ainda formas distintas". Enquanto Giedion queria dar uma interpretação racionalizante das "máscaras historicistas" de que se reveste o século da burguesia triunfante, mostrando como eles pré-anunciam as melhores obras do "modernismo" arquitectónico (Le Corbusier, os arranha-céus, etc.), Benjamin reve1a que o "passado", "o-quefoi-uma-vez" (das Gewesene) das máscaras é muito actual. Assim, oferece uma topografia de zonas intermédias: as "casas oníricas do colectivo: passages, jardins de inverno, panoramas, fábricas, museus de cera, casinos, estaçōes" (24).

> Aquilo que era interioridade (burguesa), tranquilidade, segurança, intimidade (die Gemütlichkeit), lugar do sono e sonho do lugar, enfim o Intérieur, transforma-se em exterior: "O Intérieur avança para o exterior. É como se o burguês estivesse tão seguro do bem-estar a ponto de desdenhar a fachada, como que a afirmar: a minha casa, por onde quer que se seccione, é sempre uma fachada" (25). Vêem à mente os famosos cortes de casas parisienses, publicados várias vezes no dezanove. Enquanto isso é concluída uma viragem do avesso: "As passages são casas ou corredores que não têm 1ado exterior - como o sonho"(26), e "o interior do museu apresenta-se como intérieur elevado à potência"(27).

> A história praticada como acordar conduz à individualização de imagens: não bastará captar o valor dessas imagens como índice histórico no interior de uma época determinada, mas é necessário demonstrar o interesse da sua actualidade(28). Na visão essencialmente estética da obra historiográfica, como é caracterizada por Benjamin, as imagens "só adquirem legibilidade em época determinada" (29), e o presente é determinado pelas imagens suas contemporâneas. "Não é que o passado (das vergangene) esclareça o presente (das Gegenwärtige) ou o presente esclareça o passado, mas imagem (Bild) é aquilo onde o-que-foi (das Gewesene) se une fulminantemente com o tempo de agora (Jetztzeit) numa constelação. Por outras palavras: imagem é a dialéctica na suspensão de movimento (Bild ist die Dialektik in Sti17stand). Já que enquanto a relaçăo do presente com o passado (das vergangene, como 
categoria tempora1) é puramente tempora1, a de o-que-foi (das Gewesene) com o agora (das Jetzt) é dialéctica: não de natureza temporal, mas de natureza figurativa (bildlich, figurado). Só as imagens dialécticas (dialektische Bịder) são imagens autenticamente históricas, isto é não arcaicas"(30). E "o lugar, nas quais se encontram, é a linguagem (die Sprache)"(31). A sincronicidade de presente e imagem significa que "cada agora (das jetzt) é agora de uma reconhecibilidade (das Jetzt der Erkennbarkeit) (32). No instante em que se faz imagem com o presente, o o-que-foi produz conhecimento. A imagem é a única relação histórica (geschichtlich e não zeitlich) do passado de o-que-foi (das Gewesene) com o agora (Jetztzeit).

> Para Benjamin, o historiador deve alcançar um momento de condensação da realidade, uma sua precipitação, que se revela no instante fulminante "no qual cada passado (no seu tempo) pode obter um grau de actualidade (Aktualität) mais alto que o momento da sua existência" (33). operação surpreendente, a de Benjamin, que, com a intençăo de renovar as estradas do "materialismo histórico", de tentar reparar as suas insuficiências, de facto mina-o pela base e quase o esvazia. Nasce um novo modo de "praticar" a história, que evita as armadilhas de um relativismo histórico com a sua crença cega nas ideias "logo-centricas" e antropo-centricas de movimento, de progresso e de evolução. Benjamin invocou uma história que prescinde da reverência atribuída aos grandes nomes, aos ídolos da velha história - ídolos políticos, cronológicos e individuais - e, abrindo os "caixotes do 1ixo", endereça-os para novos objectos: o horizonte da civilização material e tecnológica, a multidão das figuras desconhecidas, os efeitos da repetição no interior de uma longa série.

> Năo é casual que precisamente nesses anos Martin Heidegger iniciou as suas pesquisas sobre a origem da noção de "história do sentido" e sobre a determinação de ordem ontológico-temporal que 1igasse o agora (Jetzt), o presente (Gegenwart) e a presença (Anwesenheit).

> A Teitura do texto de Benjamin obriga-nos a (re)pensar na possibilidade actual da história (e do projecto), na historicidade das noçöes de história e de projecto. Parece-nos que só este tipo de leitura poderá vencer as "resistências" que hoje, sob pretextos e alibis diversos, procuram reinstalar os dogmas do humanismo mais banal, enquanto as instituições mantêm o seu silêncio irracional. ecos 
Walter Benjamin, Das Passagen-werk, Gesammelte Schriften, v, 1 e 2, ao cuidado de Rolf Tiedmann, Suhrkamp Verlag. Frankfurt-an-Main 1982; ed. it. Parigi, Capitale del XIX secolo, Einaudi, Torino 1986.

R. Bischof, E. Lenk, L'intrication surréelle du rêve et de T'histoire dans les passages de Benjamin, colloque internationale, 27-29 junho 1983. editado por Heinz Wismann, Cerf, Paris 1986.

Aragon, Le paysan de Paris, Gallimard, Paris 1926.

Jacques Rancière, Les noms de 1 'histoire. Essai de poétique du savoir, Seuil, Paris 1992.

Jacques Derrida, "Ouisia et gramé. Note sur une note de sein und zeit", in Marges de la phi losaphie, Minuit, Paris 1972.

Jacques Derrida, "Cogito e storia della follia", in La scritura e la differenza, Einaudi, Torino 1971.
1 wa7ter Benjamin, Das Passagen-Werk. Gesam-melte schriften, v. I e 2. ao cuidado de Rolf Tiedermann, Suhrkamp verlag, Frankfurt-an-Main, 1982, cd. it. Parigi. Capitale del XIX secolo, Einaudi. Torino 1986. a partir de ago-ra PC[N2, 6]

$2 \mathrm{PC}[\mathrm{N} 2,6]$

$3 \mathrm{PC}[\mathrm{N1a}, 8]$

$4 \mathrm{PC}[K 1,3]$

$5 \mathrm{PC}[K 2 \mathrm{a}, 1]$

$6 \mathrm{PC}[\mathrm{K} 2 \mathrm{a}, 1]$

7 PC[K1, 4]

8 PC $[N 3 a, 2]$

$9 \mathrm{PC}[\mathrm{k} 1 \mathrm{a}, 6]$

10 PC[KIa, 1]

11 PC [N2a, 1]

$12 \mathrm{PC}[\mathrm{N} 1,9]$

$13 \mathrm{PC}[\mathrm{N} 1,11]$

$14 \mathrm{pC}[\mathrm{N1a}, 5]$

$15 \mathrm{PC}[\mathrm{K} 1,2]$

$16 \mathrm{PC}[\mathrm{K} 1,2]$

$17 \mathrm{PC}[K 8,1]$

$18 \mathrm{PC}[\mathrm{K} 1,2]$

$19 \mathrm{PC}[02 \mathrm{a}, 1]$

$20 \mathrm{PC}[\mathrm{C} 3,5]$

$21 \mathrm{PC}[\mathrm{FO}, 34]$

22 PC [K1. 5]

$23 \mathrm{PC}[\mathrm{K} 2 \mathrm{a}, 4]$

$24 P C[L 1,2]$

$25 \mathrm{PC}[\mathrm{L} 1,5]$

26 PC $[L 1 a, 1]$

27 PC [L.1a, 2]

28 PC $[K 2,3]$

$29 P C[N 3,1]$

$30 \mathrm{PC}[\mathrm{N} 3,1]$

31 PC $[\mathrm{N} 2 \mathrm{a}, 3]$

$32 \mathrm{PC}[\mathrm{N} 3,1]$

33 PC [K2, 3] 


\section{notas à tradução.}

o texto apresenta-se em duas versões: em inglês e em italiano; de uma forma geral privilegiou-se o texto inglês, aferindo conteúdos pelo italiano.

Sempre que possivel foram comparadas as diferentes versões de traduçăo do texto de Benjamin. No entanto e para alguns dos termos, surgem dificuldade concretas decorrentes dos múttiplos significados que alguns dos termos usados comportam.

Encontram-se neste caso:

- der Abfal1; este termo significa refugo, mas refugo no sentido do que sobra de uma operação (descascar batatas, p.ex.); der Abfal1 não tem uma conotação negativa, como em português resíduo; a expressão é usada também para materiais dos quais se pode fazer outras coisas (como por exemplo trapos/uma boneca de trapos); este segundo sentido parece ser importante no texto original, já que Benjamin procura reciclar esse refugo para construir novos instrumentos de análise histórica; de uma forma mais rigorosa poderia traduzir-se por "rebotalho" ( já que em inglês refuse/garbage têm também este significado), mas rebotalho é uma palavra em desuso; optou-se assim em traduzir por resíduos.

- das Gewesene; significa o acontecido; poderia ser traduzido por "outrora" (por exemplo na edição francesa de Passagen-Werk, Jean Lacoste traduz por Autrement, o que legitimaria esta opção); no entanto, no texto da Lotus, Teyssot faz traduzir por "what-once-was"/"ciòche-c'era-una-volta" acentuando a pertença ao verbo ser.

- Schwelle; significa, entre outras coisas, Timiar; pelo sentido do texto poderia também ser traduzido por umbrał ou soleira já que também comporta este significado arquitectónico, aliás como seui1 ( $\mathrm{fr}$. ), sog7ia (it.) e threshold (ing1); no entanto manteve-se com a significação mais 1ata, já que aparece na relação "1imite/1imiar" assim como "limiar da consciência", năo obliterando no entanto, o significado espacial. 